\title{
Management of the Educational Change in the Covid 19 Pandemic Era
}

\author{
Lenie Okviana ${ }^{1 *}$ Ismi Dwi Astuti Nurhaeni ${ }^{2}$ \\ ${ }^{1,2}$ Faculty of Social and Political Sciences ,UniversitasSebelasMaret, Surakarta, Indonesia \\ ${ }^{*}$ Corresponding author.Email:lenieokviana@gmail.com
}

\begin{abstract}
The challenge of the Industrial Revolution 4.0 became very concrete for the world of Education in Indonesia after the government approved the new platform for the Freedom to Learn policy. Many technical aspects, for example, related to facilities, must be prepared. In short, the policy feels too fast to make, while the response feels slow. 2020 is a serious challenge to the implementation of Education in Indonesia. In general, the stuttering education program lent the Freedom to Learn offered by the government as well as a pandemic effect 19 that suddenly occurred. The problem is related to readiness and various other problems. This article will analyze how to manage human resources as educators in changing learning methods that change. How is government communication, education with the public using conventional learning is now? The method used in this study was research literature (literature research). Kurt Lewin's Theory of Culture and Theory of Change were used to answer the debate.
\end{abstract}

Keywords: Change, Freedom of Learning, Educational Institutions, HR teaching staff, communication.

\section{INTRODUCTION}

The Challenge of Industrial Revolution 4.0 became very concrete for the world of Education in Indonesia after the government established a new platform for Freedom-toLearn policy [5]. Many technical aspects, such as facilities, must be prepared. Succinctly, policies feel too quickly to be created, while responses feel slow. 2020 is a tough challenge for the implementation of Education in Indonesia. In general, education stuttered in response to the Government's Freedom-to-Learn program as well as the sudden effects of the COVID-19 pandemic. The problem is related to readiness and various other obstacles.

This context does not see the process of Industrial Revolution 4.0 equivalent to futurologists that takes place evolutionarily, slowly, and measurably or can be anticipated. There is a time that leaves a preparatory space for the community to respond to developed countries affiliated with the Organization for Economic Cooperation and Development (OECD) that have been prepared for it for approximately 20 years since 1994 (OECD, 1996) [7]. "Immediate" in Industrial Revolution 4.0 is a processual and gradual/gradual change. Besides, the element of speed in the context of Industrial Revolution 4.0 is limited only to the flow of information dissemination.

The COVID-19 pandemic has accelerated the digital transformation process of its education management and learning practices, which have been single-tracked as a result of the demands for the advancement of digital information technology. By contrast, advances in digital information technology have become a "god of help" for education whose conventional practices have been forced to stop due to pandemic attacks. Thus, pandemic disruptions cannot be read outside the context of the Industrial Revolution 4.0. On the other hand, the understanding of Industrial Revolution 4.0 cannot be limited only to technological disruption processes. There is a non-technology aspect, in this case, the COVID-19 pandemic which also played a decisive role in the revolutionary transformation process of education. The current paradigm shift in education is the interface between the thrust of Industrial Revolution 4.0 and the direct impact of the COVID-19 pandemic.

As of April 17, 2020, an estimated 91.3\% or about 1.5 billion students worldwide are unable to attend school due to the emergence of the Covid-19 pandemic [8]. That number includes approximately 45 million students in Indonesia or about $3 \%$ of the globally affected student population (Central Bureau of Statistics, 2020). The widespread of Covid-19 has forced the government to close schools and to encourage distance learning at home. Various initiatives are taken to ensure that learning activities continue despite the absence of face-to-face sessions. 
Technology, more specific internet, smartphones, and laptops are now widely used to support distance learning. One of the largest telecommunications service providers in Indonesia recorded $16 \%$ increase in broadband flow during the Covid-19 crisis, caused by the sharp increase in the use of distance learning platforms. However, disruption to the traditional education system has harmed students from disadvantaged families and those in rural areas. They are students who, even under normal conditions, already face barriers to accessing education. Now they need to face additional barriers that arise from inequality to access technology infrastructure.

Indonesia's topography of islands and mountains requires the procurement of internet and mobile telecommunications. However, $4 \mathrm{G}$ coverage is mostly concentrated in Java because mobile telecommunications service providers relying heavily on the market, of course, prioritize urban areas over rural areas with fewer populations [3].

The sudden change from face-to-face methods in the classroom to distance learning at home also demonstrates the need for improved educator capabilities. [11] Some research shows that the competence of information, communication, and technology (ICT) of Indonesian educators is not evenly distributed throughout the region (Widodo \&Riandi, 2013 quoted from Koh et al, 2018). What's more, there is a gap in the quality of education throughout Indonesia, especially between Java and beyond Java, and among socio-economic conditions [1][6]. Uneven internet access, educator quality gaps, and quality of education, and lack of ICT skills are vulnerabilities in remote learning initiatives in Indonesia.

This article will analyze how to manage the readiness of human resource such as educators for the changing learning methods and how the government and educational institutions communicate with people who have been accustomed to conventional learning to change into home learning.

\section{LITERATURE REVIEW}

This article will discuss some theories related to topic discussed; the authors attribute the culture and organizational structure in preparing or adapting to change. The first role of educators in the implementation of distance learning is to develop their potential and to adapt to change.

\subsection{Organizational culture}

Culture leads individuals or groups to behave and instruct them on what to follow and to learn in an organization. Nanus \& Dobbs entails the values and basic assumptions of members of the organization that determines how a job is run. Organizational culture determines how organizational energy and organizational structure give an idea that organizational culture is realized because it is created by individuals who have a common basic assumption pattern to determine how a job is carried out and how an organization's problems are solved, both external and internal [4].

That culture is accepted as beliefs and values that must be maintained and transmitted to new employees or members in developing themselves and behaving as members. Thus it is clear that the culture of the organization can be used as a foundation and a strong foundation for the organization to continue to stand and survive in carrying out its activities (survival) and developing itself (to growth).).

The cultural development of the organization is essentially determined by the vision, mission, and purpose of the organization. As stated Iman Sudirman [9], the culture of the organization that should need to be developed by the organization is the culture of the organization following the vision, mission, and purpose of the organization.

\subsection{Model Changes}

Regarding this crisis handling, the author looked at it using the Kurt Lewin model, Kurt Lewin's Theory.

Kurt Lewin's change model was put forward in the 1950s known as the Unfreeze - Change - Refreeze model. With a background as a social scientist (earning a Ph.D in science and psychology), Lewin built a model of change that could be explained using the shape-changing analogy of a chunk of ice spanning 3 stages. With the analogy it is simply described that if a person has a hunk of ice in the form of a cube and wants the shape of the ice to be a taper ED shape (cone) then first the chunk of ice must be melted so that it is easier to unfreeze, then the ice that has melted is inserted into the mold according to the desired shape and size (change) and then refreeze) [10].

By looking at the process of change in different stages, the necessary planning can be better prepared. In concept, it is easier to understand and implement because the desired direction and shape of change have been seen and determined. Unplanned changes will bring the organization to the point of darkness and can cause very violent shocks and even chaos that could potentially destroy the organization.

To start a successful process of change it is necessary to know clearly why a change is necessary because it is the basis and strong reason to implement it. Lewin asserts that the motivation for change must be built first before the process of change itself takes place. Everyone should help each other to validate the assumptions built to run the organizational change process. This is the unfreeze stage in which the process of organizational change will begin from that point.

In a more operational form, the unfreezing process is carried out by preparing the willingness and readiness of all elements of the organization to believe that change is necessary by disclosing various status quo- situations before building on new business processes. Things that can be used as an issue to reassure this for example by showing a decreased level of sales, deteriorating financial condition of the organization, a decrease in customer satisfaction obtained based on the survey results, higher 
product returns, and other similar things. All important issues raised as themes and reasons for change should concern things that are easy for everyone to understand so that the necessary change plans can be well understood.

To prepare for such a change successfully, it takes the courage of leaders to challenge the status quo situation over fundamental matters, such as concerning the beliefs that have been embraced by the organization, the prevailing values in the organization, the attitudes and behaviors of the elements within the organization. Changes to such fundamentals must be well prepared to support the long-term viability of change and the organization does not experience worse circumstances while the process of change is underway. It is acknowledged that the processes at this stage are very difficult and stressful due to the many harsh reactions from various elements of the organization to reject them. But it takes courage and toughness of top management to dampen all those reactions because it is a necessary action and worth the benefits that want to be achieved.

By forcing all elements of the organization to retest the fundamental aspects of the organization, the control over the current crisis conditions within the organization can be done effectively. Besides, communicating the vision of change in the right way will form a strong motivation for most parties in the organization to acquire new values. With the characteristics of forcing a change in the desired direction, Kurt Lewin's change management approach is often also called the Force-field Model. The emphasis needs to be put on this, especially towards people who have a key role in determining the course of the organization's trial process.

Furthermore, at the next stage, a change is made where everyone is involved in finding new ways to do the job more effectively and efficiently. It is at this point that all members of the organization begin to have trust and act in new ways to support the achievement of the organization's new direction and goals. The change from the first stage to the second stage takes a long time as various adjustments often require little detail. In this second stage, another thing that also cannot be ignored is how to translate that change benefits individuals collectively, and not solely for the benefit of the organization.

Change should not run only for the benefit of change itself. Therefore the availability of time and two-way communication lines are the two main keys for change to be successful. Everyone should have strong relationships and engagement as the process of change progresses. At this stage, all elements of the organization must be empowered in order for the change process to run optimally. In this case the involvement of the top management directly in any change motion is the best approach. In addition, senior leaders must manage various issues concerning doubts and difficulties experienced by various parties. Therefore, in the circumstances and the process of change, leaders must open a good line of communication to accommodate and resolve various complaints that arise related to the ongoing process of change. At this stage, it is highly recommended not to open up opportunities for doubt among employees about the continuity of the change process.

By the last stage when change has reached its desired shape, all elements of the organization are already fused with new ways to work. Signs that the organization has entered this stage occur when stability has been reflected in the organizational structure, description and implementation of work running consistently, the weaknesses that previously occurred began to be resolved, there has been an improvement in the performance of the organization in various other positive things. However, aspects of the changes that have been achieved need to be maintained at all times and therefore all elements in the organization must be integrated into each organization's daily activities.

\subsection{Communication and collaboration}

An active form of participation for learning and research is through digital networking. Communication and collaboration as part of the digital literacy element are interpreted as that there is active participation in digital networks for learning and research. While according to Stefani, communication and collaboration is the active participation of digital media users to streamline time, it is closely related to media as digital that has convergence [8]. Communication and collaboration have individual competence components consisting of use skills which are the ability to access and operate media, critical understanding in the form of the ability to analyze and evaluate media content comprehensively and, communicative abilities namely communication and participation capabilities through media [2].

\section{METHODS}

The method used for this article is a literature review. Data collection techniques were used to read and record and process material, to explore several journals, books and documents (both printed and electronic) as well as other sources of data or information deemed relevant to the study.

\section{RESULTS AND DISCUSSIONS}

\subsection{Managing human resource readiness as an educator in change}

Human resource readiness relates to the culture of the organization applied. Culture leads individuals or groups to behave and instruct them on what to follow and learn in an organization. The culture of conventional Education organizations must now change and be followed by its members in this case the ability of educators to literate technology. That culture is accepted as beliefs and values that must be maintained and transmitted to new employees or members in developing themselves and behaving as members. Thus it is clear that the culture of the organization can be a strong foundation and foundation for the organization to continue to stand and survive in 
carrying out its activities (survival) and developing itself (to growth)).

The role of the first educator in the implementation of distance learning is to develop learning content. To do so, educators must of course think that the learning content will be delivered online. This assumption is crucial in content development for distance learning. Then, educators also need to define the components of the learning content, consider and pay attention to existing learning content, and finally develop it.

As mentioned earlier, the assumption that learning content is delivered online is important in developing content for distance learning. With that in mind, educators should be aware that the goal of distance learning is to replace the experience of face-to-face learning in the classroom. Also, in contrast to face-to-face learning, the facility of educators to their students will be centered on online software and applications. Students in this learning system are also assumed to be self-reliant or less reliant on the direct assistance of educators. After paying attention to the assumptions of distance learning, educators are ready to develop their learning content. The components in the learning content that need to be developed. This can be done by conducting training for educators to be proficient in using distance learning technology. If the organization is experiencing problems, top management will have to take a concrete strategy.

The most crucial obstacle, in this case, is the educators who are 40 years old and older, the fact that there are still many who are not yet literate about technology so need to adapt to the new teaching culture. Communication and collaboration are needed as part of the digital literacy element, to assist the complicit individuals who can access and operate media (use skills, critical understanding and, communicative abilities.) [2]

\subsection{Communication of Educational Institutions with the Community related to School Changes}

The authors look at the state of the crisis during the Covid19 pandemic. The government, in this case the Ministry of Education, needs to apply the Kurt Lewin's theory. Kurt Lewin's revamp is known as the Unfreeze - Change Refreeze model. Unfreeze process is done by preparing the willingness and readiness of all elements of the organization to believe that change is necessary by expressing various status quo situations before building on new processes. Before Covid19, the Minister of Education had established the Freedom-to-Learn program, so the learning pattern was certainly changed. Therefore, all elements of the organization (from educational institutions as well as the community) must be ready to change. Changes in distance learning methods are certainly extended due to the effects of Covid-19.

The Change process or the change successfully takes the courage of the leader to challenge the status quo situation over fundamental things. The Minister of education dared to make changes. Vision and Mission created to create a happy learning atmosphere without being burdened with the achievement of scores or scores. It is acknowledged that the processes at this stage are very difficult and stressful due to the many harsh reactions from various elements of the organization to reject them. But it takes courage and toughness of top management to dampen all such reactions because it is a necessary action and worth the benefits that want to be achieved.

It takes a lot of money to make changes, this pressure is precisely dating from the Covid-19 outbreak, so it inevitably forces everyone to change in the process of learning and teaching. The emphasis on change spurs stakeholders to create new policies.

The change should not run only for the benefit of change itself. Therefore the availability of time and twoway communication lines are the two main keys for change to be successful. Governments and educational institutions must carry out this process, so that information sharing does not occur and policies can be accepted by the public.

\section{CONCLuSiON}

Human resource readiness relates to the culture of the organization applied. Culture leads individuals or groups to behave and instruct them on what to follow and learn in an organization. The culture of conventional Education organizations must now change and be followed by its members in this case the ability of educators to literate technology. That culture is accepted as beliefs and values that must be maintained and transmitted to new employees or members in developing themselves and behaving as members. Thus it is clear that the culture of the organization can be a strong foundation and foundation for the organization to continue to stand and survive in carrying out its activities (survival) and developing itself (to growth))

The first role of the educator in the implementation of distance learning is to develop learning content. To do so, educators must of course think that the learning content will be delivered online. This assumption is crucial in content development for distance learning. Then, educators also need to define the components of the learning content, consider and pay attention to existing learning content, and finally develop it. Communication and collaboration are needed as part of the digital literacy element. To assist the complicit individuals who can access and operate media (use skills, critical understanding and communicative abilities.)

Kurt Lewin's revamp is known as the Unfreeze Change - Refreeze model. Unfreeze process is done by preparing the willingness and readiness of all elements of the organization to believe that change is necessary by expressing various status quo situations before building on new processes. The change should not run only for the benefit of change itself. Therefore the availability of time and two-way communication lines are the two main keys to the successful change. Governments and educational institutions must carry out this process, so that information 
sharing does not occur and policies can be accepted by the public.

\section{REFERENCES}

[1]Azzizah, Y. (2015). Socio-Economic Factors on Indonesia Education Disparity. International Education Studies. 8(12). 218-230.

[2] Commission, F. the E., \& Unit, D. G. I. S. and M. M. L. (2009). Study on Assessment Criteria for Media Literacy Levels. Framework

[3]Khatri, H. (2019). Indonesian users in sparsely-populated urban areas connect to $4 \mathrm{G}$ more than $70 \%$ of the time. Opensignal.

Diambil dari: https://www.opensignal.com/2019/11/12/indonesian-users-insparsely-populated-rural-areas-connect-to4g-more-than-70-of-the-time

[4]Katherine Miller, Organizational Communication: Approaches and Processes, 6th ed

[5] Ministry of Education, 2020, January 24, "Minister of Education launches four independent learning policies: Independent campus". https://www.kemdikbud. go.id/main/blog/2020/01/mendikbud-luncurkan-empatkebijakanmerdeka-belajar-kampus-merdeka.

[6] Muttaqin, T. (2018). Determinants of Unequal Access to and Quality of Education in Indonesia. The Indonesian Journal of

Development Planning. 2(1). 1-20.

[7] Organization for Economic Cooperation and Development, 1996, Mapping the future: Young people and career Guidance, OECD, Paris.

[8] Stefani, S. N. B. (2017). Digital Literacy and SelfOpening: Correlation Study of Social Media Use in Adolescent Students in Medan. Socioglobal, Journal of Sociological Thought and Research,2(1), 10-31.

[9] Sudirman, Iman. 2005. Organizational Culture. Hand Out.

[10] Tanner, Robert. (2017). Unfreeze, Change, Refreeze: Is This a Child's Game? Taken from: https://managementisajourney.com/

[11]Widodo, A., \& Riandi. (2013). Dual-mode teacher professional development:

challenges and re-visioning future TPD in Indonesia. Teacher

Development,

17(3), 380-392 